\title{
Investor Valuation of the Abandonment Option: Empirical Evidence from UK Divestitures 1985-1991
}

\author{
Ephraim Clark \\ Middlesex University Business School and GERME Esa/Esc Lille, U.K. \\ Magid Gadad \\ The Academy of Graduate Studies, Tripoli \\ Patrick Rousseau \\ Université Aix-Marseille, France
}

This paper looks at divestitures by 144 UK firms listed on the London Stock Exchange from 1985 to 1991 and investigates whether and how accurately investors price the firm's option to abandon assets in exchange for their exit value. Theory prices this real option as an American style put and the model we test includes the major features of the abandonment option literature: stochastic firm value, stochastic exit value, intermediate cash flows and uncertain project life. It also includes random events that can short circuit the optimal timing of the divestiture and trigger abandonment prematurely. The empirical implications are that investors do price the abandonment option but that they price it imperfectly because the exit price is private information. There is evidence that the effects of the timing factor are accurately priced and that the probability of forced premature abandonment figures in the option pricing. (JEL: G13, G33, G35, M41)

Keywords: real options, abandonment, divestiture, premature abandonment, abnormal returns

\section{Introduction}

Using balance sheet information to deduce the firm's exit value, Berger,

(Multinational Finance Journal, 2010, vol. 14, no. 3/4, pp. 291-317)

(C) Multinational Finance Society, a nonprofit corporation. All rights reserved. DOI: $10.17578 / 14-3 / 4-5$ 
Ofec and Swary (1996) found strong evidence that US investors do price the abandonment option and that this price is reflected in the firm's equity value. A major unresolved question, however, is how accurately the option can be priced. This is because the actual exit value is typically negotiated in strict confidentiality by the management teams of the divesting and acquiring firms. Thus, the exact exit value, which is necessary to accurately price the abandonment option, should remain private information until the deal is actually announced. ${ }^{1}$ The empirical evidence on private information and insider trading rejects the strong form of the efficient market hypothesis $(\mathrm{EMH}){ }^{2}$ Consequently, if it is true that the strong form of the EMH does not hold and that the exact amount of the exit value is private information, investors should not be able to price the abandonment option accurately until the private information becomes public.

This paper uses event study methodology applied to divestitures by 144 UK firms listed on the LSE from 1985 to 1991 to investigate: 1) whether UK investors price the firm's American style put option to abandon assets in exchange for their exit value; 2 ) how accurately they price it; and 3) if the option is mispriced, is the mispricing due to the private nature of the information surrounding the exit value or are there other factors at work.

The abandonment option has been discussed for over 30 years as a control problem where real option theory has it that corporate managers act to time their strategic decisions in an optimization framework that maximizes the expected value of the firm. Robichek and VanHorne (1967), corrected by Dyl and Long (1969) include the abandonment option as a contingency in their forecast of cash flows for traditional net present value or internal rate of return analysis. Margrabe (1978) and Stulz (1982) model the option directly and consider two risky

1. The completion date of divestitures is often the same as the announcement date of the divestiture. The reason for this is that a large number of divestitures do not require shareholder approval and are therefore "announced" at a later stage in the legal process or after legal completion. However, Afshar et al. (1992) and Klein (1986) have pointed out that announcements can also refer to intent to divest rather than completion. Thus, the correct completion date is impossible to determine. The completion date, however, can be the date when shareholder approval has been received (if necessary), or when regulatory approval has been received or when final sale and purchase contracts are signed. Since our study is concerned with private information, we are interested in the date that the private information becomes public, i.e. the announcement date.

2. For a detailed review of the empirical evidence on insider trading, see Arshadi and Eyssell (1993). 
non-dividend-paying assets. Johnson (1987) extends the analysis to several risky assets. Brennan and Schwartz (1985) develop shut down-abandonment decision rules at known intervals based on a constant salvage value and the price of the underlying commodity while McDonald and Siegel (1985) consider costless, temporary shutdowns in their risk neutral evaluation of a dividend paying investment project with a known life. Myers and Majd (1990) use numerical methods to value the option to permanently abandon a dividend paying investment project at any time over the project's known life when the salvage value is a constant and when it varies stochastically. Dixit and Pindyck (1994) consider an infinitely lived dividend paying investment with constant salvage value and derive rules for optimal abandonment.

In contrast to the foregoing theoretical studies, our study contributes to the empirical side of the real options literature, which is relatively undeveloped. ${ }^{3}$ Besides testing whether the abandonment option is priced in the UK, we also test how accurately it is priced and what causes any mispricing that shows up. The model we develop and test incorporates all the major features of the abandonment option literature such as stochastic exit value, intermediate cash flows, dividends and uncertain project life. Besides the testing itself, one of the novelties of the paper is that the model also includes a stochastic jump process that triggers abandonment prematurely. This process is designed to capture the effect of random events with overriding imperatives that short circuit the maximizing behavior of managers. For example, a firm might be forced to sell off valuable assets before reaching what would otherwise be the optimal abandonment point because of a liquidity crisis, a regulatory change, the arrival of a major competitor, the threat of a hostile take-over or even a minor strategy switch such as a switch from in-house production to out-sourcing.

Our paper also contributes to the large body of divestiture research that attempts to identify value relevant motives for divesting. In fact, the literature offers a wide range of motives for undertaking a divestiture. Kaplan and Weisbach (1992), for example, suggest it can be motivated by a change in corporate strategy. Lang, Poulsen and Stulz (1995)

3. Besides Berger, Ofek and Swary (1996), other empirical testing of real option theory such as Paddock, Siegel and Smith (1988) on the value of offshore oil leases and Quigg (1993) on the value of land concentrate on the value of waiting rather than the value of abandonment. Darby et al (1999) include both waiting and abandonment to test for the effect of exchange rate volatility on the level of aggregate investment. However, the Darby et al. (1999) paper has a fundamental mathematical error and several conceptual inconsistencies that call the value of their results into question. 
explain divestiture as a source of cash to reduce firm debt. John and Ofek (1995) propose the fit hypothesis and John and Ofek (1995) and Comment and Jarrel (1995) propose the focus hypothesis while Lasfer, Sudarsanam and Taffler (1996) highlight financial distress and bankruptcy avoidance. Agency costs and strategic considerations have been suggested by Kaiser and Stouraitis (2001), Teheranien, Travelos and Waegelein (1987) and Hirschey and Zaima (1989). Other motives include information asymmetry, synergy, tax, wealth transfer, and removal of inefficient management. The bulk of the empirical evidence on divestitures indicates that divestiture announcements are associated, on average, with positive wealth effects. ${ }^{4}$ Within the possible explanations, the empirical tests of Kaiser and Stouraitis (2001) highlight the importance of focus and the disposal of loss making assets to explain wealth gains associated with corporate selloffs while Alexandrou and Sudarsanam (2001) emphasize the importance of both firm specific and environmental factors.

In contrast to the foregoing studies, our examination of the abandonment option stresses the timing of the divestiture and the subsequent effect of releasing the formerly private information that reveals the true value of the abandonment option.

The abandonment option is equivalent to an American style put option on a dividend paying stock with a stochastic strike price and no expiration date. Our analysis of this option leads to predictions about how option values, exit values and timing factors affect firm value and cumulative abnormal returns (CARs) around the announcement date of the divestiture. It is based on the following argument: If the strong form of EMH holds or if the exit value is not private information, the option value will be fully priced by investors and there will be no statistical relationship between CARs and the elements of the option pricing formula developed in section II. If, on the other hand, the strong form of EMH does not hold and exit value is private information, the option will not be fully priced by investors and there will be a significant statistical relationship between CARs and the elements of the option-pricing model. A significant one for one relationship between

4. See, for example, Kummer (1978), Rosenfeld (1984), Hearth and Zaima (1984), Jain (1986), Klein (1986), Hite, Owers, and Rogers (1987), Tehranian, Travlos and Weagelein (1987), John and Ofek (1995) and Lang, Poulsen and Stulz (1995) for the USA and Afshar, Taffler and Sudarsnam (1992) and Gadad (1998) for the UK. Boudreaux (1975), Denning (1988) and Montgomery, Thomas and Kamath (1984) report positive and insignficant shareholder wealth effects. The negative shareholders wealth effect on the announcement day was reported by Alexander, Benson, Kampmeyer (1984) and Denning and Shastri (1990). 
CARs (expressed as abnormal capital gains) and exit values suggests that the option has not been priced at all.

Using event study methodology on data of 144 divestitures in the U.K between January 1, 1985 and December 31, 1991 to measure abnormal returns, CARs are calculated over the relevant windows and used to estimate abnormal capital gains resulting from the divestiture. This information is then used to test whether the model developed in section II has any statistically significant explanatory value associated with the abnormal capital gains. Our results can be summarized as follows:

There is evidence that investors do attempt to price the abandonment option.

There is evidence of frequent premature abandonment.

The results indicate that the timing factor is not statistically significant in explaining variations in CARs. This suggests that investors are generally able to accurately assess the effects of the timing factor and use it in assessing the value of the abandonment option.

When the probability of premature divestiture is included in the timing factor it generally weakens the regression results in both the significance of the coefficients and overall explanatory power $\left(R^{2}\right)$. The timing factor that includes the probability of premature divestiture is not significant as a stand-alone variable for any of the windows. This is weak evidence that the possibility of premature divestiture does play a role in the abandonment decision and the value of the option. If it does play a role, its effect is accurately assessed by investors.

The rest of the paper is organized as follows. In section II the model is developed. Section III describes our data and methodology and section IV presents our results. Section V concludes.

\section{The Model and its Implications}

Our model incorporates all the major features of the abandonment option literature that lends it realism such as stochastic sales price (exit 
value), intermediate cash flows and dividends and uncertain project life. It also includes a stochastic jump process that triggers abandonment prematurely.

\section{A. The value of the divestable asset when the abandonment option is} fully priced

Consider a divestable asset whose value at time $t$ in the absence of the abandonment option, defined as the present value of the divestable asset's expected cash flows, is $V(t)$ and follows geometric Brownian motion $^{5}$

$$
d V(t)=\alpha V(t) d t+\sigma V(t) d z(t)
$$

where $a$ is the growth rate of the value of the investment, $d z(t)$ is a Wiener process with zero mean, and variance equal to $d t$, and $\sigma^{2}$ is the variance parameter of the percentage change of $V(t)$.

Now consider the exit value (sales price) denoted by $S$. This value is unlikely to remain constant and changes will very probably be determined, at least in part, by stochastic innovations. This will be the case for any assets whose value is determined by market forces. Land and buildings fall in this category, as does equipment with a secondary market. Synergies, complementarities, managerial expertise and the needs of potential purchasers are also subject to unforeseen changes. Furthermore, technological change, legislation and other political events can affect exit value and all have a random element. With this in mind, let $S$ follow geometric Brownian motion

$$
d S(t)=\pi S(t) d t+\omega S(t) d w(t)
$$

where $\pi$ is the trend parameter, $\omega^{2}$ is the variance parameter of the percentage change in $S(t)$ and $d w(t)$ is a Wiener process with zero mean and variance equal to $d t$, with $d z(t) d w(t)=\rho d t$ where $\rho$ is the instantaneous correlation coefficient between $V$ and $S$.

Let $F$ represent the value of the divestable asset that includes the full value of the abandonment option. ${ }^{6}$ It is a function of $V$ and $S$ :

5. By divestable asset we refer to an accounting entity that could be a simple project, a division or a complex subsidiary.

6. We can consider $F$ as the value of the divestible asset to the firm. Since the firm has 


$$
F=F(V(t), S(t))
$$

The problem facing managers of the divesting firm is to exercise the option to divest by actually divesting at the most advantageous time. By acting too soon, time value in the option will be lost. By waiting too long, intrinsic value will be lost. As we will see when we solve equation (3) (see Appendix), there will be a point determined by $V$ and $S$, call it $g^{*}$, where it will be optimal to abandon the project. However, it is also possible that abandonment could be triggered by an external event with overriding strategic imperatives such as a liquidity crisis, a regulatory change, a hostile take-over bid, a minor reorganization, etc. that occurs before the optimal abandonment value of $g^{*}$ is reached. Events such as these are random and relatively rare by definition. They short circuit the maximizing procedure and cause a premature exit from the investment; that is, they cause abandonment of the assets before the optimal abandonment point at $g^{*}$ and cause a loss in the option's time value. Rare, random, discrete events are typically modeled as Poisson arrival processes.

Define $q$ as a random variable that increases by steps of 1 every time a Poisson event occurs and $\gamma$ as a constant intensity parameter such that:

$$
d q(t)=\left\{\begin{array}{l}
1 \text { with probability } \gamma d t \\
1 \text { with probability } 1-\gamma d t
\end{array}\right.
$$

This means that investment-ending events arrive at a rate of $\gamma d t$. The parameter $\gamma$ is the instantaneous probability of an event that causes the assets to be abandoned prematurely (before the point $g^{*}$ ). For example, suppose that analysis shows that a typical firm in a given industry can expect an unforeseen event that would cause an unplanned asset disposal (as opposed to the planned disposal at $g^{*}$ ) once every 15 years. The parameter $\gamma$ would then be equal to $1 / 15=0.067 .{ }^{7}$ When such an

access to the private information, this is the true value of the asset.

7. The relationship between $\gamma$ and the expected time between events (15 years in the example) is given as follows. In the interval $[0, T]$, the probability that no event occurs is $e^{-\gamma T}$ so the probability that an event occurs in the short interval $[T, T+d T]$ is then $e^{-\gamma T} \gamma d T$. Therefore, the expected time before the first event is $E[T]=\int_{0}^{\infty} T \gamma e^{-\gamma T} d T=\frac{1}{\gamma}$. Rearranging gives $\gamma=1 / E(T)$. 
event occurs, the investment is abandoned and the firm gives up $F$, the value of the investment with the abandonment option, and receives $S$, the exit value (sales price). The expected instantaneous cash flow is equal to $\gamma(S-F) d t$. When premature abandonment occurs, $F>S$ and there is a loss equal to $S-F$.

To find $F$, consider a new variable $g=V / S$, the value of the investment per dollar of exit value, where the time arguments have been dropped for simplicity of notation. Using equations (1) and (2) and Ito's lemma gives:

$$
d g=\mu g d t+\delta g d s
$$

where

$$
\begin{gathered}
\mu=\alpha-\pi-\sigma \omega \rho+\omega^{2} \\
\delta^{2}=\sigma^{2}-2 \sigma \omega \rho+\omega^{2} \\
d s=\frac{\sigma d z-\omega d w}{\delta}
\end{gathered}
$$

Make the change of variables $f(g, 1)=F(V, S) / S$. Let $R_{g}$ represent the required rate of return on $g$ with an instantaneous dividend or convenience yield of $\kappa$ so that $R_{g}-\mu=\kappa^{8}$ Then, with the instantaneous payout equal to $\kappa g d t$ and cash flows from premature exit equal to $\gamma(1$ $-f$ ) $d t$, going through the usual steps of setting up a riskless hedge consisting of one unit of the option and $-f^{\prime}(g)$ units of $g$ and applying Ito's Lemma gives the following differential equation:

$$
\frac{\delta^{2}}{2} g^{2} f^{\prime \prime}(g)+(r-\kappa) g f^{\prime}(g)-(r+\gamma) f+\kappa g+\gamma=0
$$

where $r$ is the known riskless instantaneous interest rate.

To solve equation (5) we need to know the boundary conditions, which depend on economic intuition. The intuition behind the boundary conditions, which are given in the Appendix, is that the value of the abandonment option gets increasingly smaller as g gets larger and that

8. The instantaneous dividend or convenience yield refers to the current yield associated with actually owning the assets. In the absence of any current yield, there would be no opportunity cost to abandonment and thus no incentive to delay it. See Dixit and Pindyck (1994) for a discussion of the role of dividends and convenience yields in real option pricing. 
the firm will abandon the investment when the present value of investment cash flows falls far enough below the exit value. At this point, the value of the investment, including the option to abandon, is equal to the exit value.

Using the boundary conditions in the Appendix, we solve equation (5) and determine the point at which it is optimal to abandon the investment

$$
f=\frac{\kappa}{\kappa+\gamma} g+\frac{\gamma}{r+\gamma}+K_{2} g^{\eta_{2}}
$$

where

$$
\begin{gathered}
\eta_{2}=\frac{-\left(r-\kappa-\delta^{2} / 2\right)-\sqrt{\left(r-\kappa-\delta^{2} / 2\right)^{2}+2 \delta^{2}(r+\gamma)}}{\delta^{2}}<0 \\
K_{2}=-\frac{\kappa}{\eta_{2}(\kappa+\gamma)} g * 1-\eta_{2}
\end{gathered}
$$

and where the optimal exit value, which we call the timing factor in the testing below, ${ }^{9}$ is given by

$$
g^{*}=\frac{\eta_{2}}{\eta_{2}-1}\left[\frac{r(\kappa+\gamma)}{\kappa(r+\gamma)}\right]
$$

Reversing the change of variables gives

$$
\begin{aligned}
F & =S f \\
& =\frac{\kappa V}{\kappa+\gamma}+\frac{\gamma S}{r+\gamma}+S K_{2} g^{\eta_{2}}
\end{aligned}
$$

Equation (10) gives the value of the divestable asset that includes the option to abandon. It is interesting to note that the parameter $\gamma$, the instantaneous probability of an event that causes the assets to be abandoned prematurely, appears in the first two terms on the right hand side of the equation as a discount factor. This occurs naturally when we

9. In the testing the timing factor is presented as $\left(1-g^{*}\right)$. 
solve equation (5) and reflects the increased uncertainty of the expected cash flows due to the possibility of premature exit. The risk premium for the increased uncertainty is equal to the probability of an event actually occurring: $\gamma$.

Thus, the first term of equation (10) represents the present value of the project's expected cash flows $\kappa V$ discounted at the risk-adjusted rate $R_{g}-\mu=\kappa$ plus a $\gamma$-premium for the risk of premature exit. The second term represents the present value of the expected cash flow resulting from premature exit $\gamma S$ discounted at the riskless rate plus a $\gamma$-premium for premature exit $(r+\gamma)$. The last term represents the present value of the option to abandon the investment if the expected cash flows fall to a certain level determined by $g^{*}$.

Table 1 summarizes the comparative statics associated with equation 10. An increase in the exit value increases the value of the divestable assets. There is also an inverse relationship between $g^{*}$ and $F$. Thus, increases in $r, a$, and $\rho$ increase $g^{*}$ and decrease $F$. The overall effect of premature exit risk $\gamma$ on $F$ is negative, although it does have a positive effect on the second term: a higher probability of premature exit increases the present value of the expected cash flow resulting from premature exit. ${ }^{10}$ Increases in $\pi$ and $\kappa$ decrease $g^{*}$ and increase $F$ while the effect of the variance of percentage changes in firm value and exit value $\sigma^{2}$ and $\omega^{2}$ can be either positive or negative depending on the values of the other parameters.

\section{B. Implications for CARs}

On the announcement date of a divestiture, the foregoing model shows that the value of the abandonment option is just equal to the exit value $(S)$. Thus, if the option is correctly priced, there should be no significant relationship between abnormal returns and the exit value. From the definition of the EMH, we can say that if the strong form of EMH holds or if the exit value is not private information, the option value will be fully priced by investors and there will be no statistical relationship between CARs and the exit value or any other elements of the option pricing formula developed in equation 10. In this case, the existence of

10. In table 1 we look at how the different parameters affect $g^{*}$, the optimal abandonment point and $f$, the value of the assets with the abandonment option. There is an inverse relationship between $g^{*}$ and $f$. Thus, increases in $r, a$, and $\rho$, increase $g^{*}$ and decrease $f$ while increases in $\pi$ and $\kappa$ have the opposite effect. The relationship of $\sigma$ and $\omega$, the volatilities of the varibles $V$ and $S$, can be positive, negative or nul depending on the values of the other parameters. 
CARs will be due to factors other than the abandonment option. If, on the other hand, the strong form of EMH does not hold and exit value is private information, the option will probably not be accurately priced by investors until the exit value becomes public information.

The foregoing model assumes that managers act to maximize firm value. Based on this, we argue that managers, who do have the private information, will exercise the abandonment option only if it is correctly priced or underpriced by investors. If it is overpriced, exercising the option will cause losses to firm value as investors adjust to the lower exit value.

With this in mind, the following conclusions and predictions about the relationship between option values, exit values and CARs (expressed as abnormal capital gains) around the announcement date of the divestiture are forthcoming.

(1) No statistical relationship between the exit value $(S)$ and CARs (expressed as abnormal capital gains) implies that the option has been fully and accurately priced.

(2) A significant, one for one positive relationship implies that the exit value was a complete surprise and the option has not been priced at all.

(3) A significant positive, less than one for one relationship implies that the abandonment option has been underpriced by investors. We predict that a significant positive, less than one for one relationship will be associated with positive CARs (expressed as abnormal capital gains).

(4) A significant negative relationship has two implications. First of all, it implies that the option has been overpriced. Second, based on the argument that managers would not exercise an overpriced option, it implies premature abandonment. We predict that a significant negative relationship will be associated with negative CARs (expressed as abnormal capital gains).

(5) If the option is being priced by investors, a significant relationship between the timing factor $\left(g^{*}\right)$ and CARs (expressed as abnormal capital gains) implies that the timing factor has been inaccurately estimated by investors. No significant relationship implies that it has been accurately estimated. 
(6) Finally, if investors are pricing the option, a significant relationship between the probability of premature divestiture and CARs (expressed as abnormal capital gains) implies that those investors have inaccurately estimated the probability of premature divestiture. No significant relationship implies that it has been accurately estimated.

\section{Data and Methodology}

\section{A. The Initial Data}

From the initial sample of 3031 corporate divestitures in the UK completed in the period from January 1, 1985 to December 31, 1991 as reported in Acquisitions Monthly there were 144 transactions that met the requirements for testing whether and how accurately the abandonment option was priced by investors.

First, since our testing concerns the UK and requires market prices and exit values we eliminated all transactions by seller firms that were not UK companies, that were not listed on the London Stock Exchange or that did not have data available for the testing period of 250 days before the divestiture announcement and 30 days after the announcement. We also eliminated all transactions that did not disclose the price of the transaction.

Second, in order to avoid confusing option exercise with other divestiture motives, it was necessary that our final sample be as free as possible of transactions that are not truly voluntary divestitures in the spirit of the optimal timing and wealth maximization reflected in the model. ${ }^{11}$ This would exclude transactions motivated by considerations such as a change in corporate strategy or financial distress. A program of sell-offs and takeovers could indicate strategic change while multiple sell-offs alone could indicate either strategic change or financial distress. ${ }^{12}$ By the same token, a

11. The consideration here is that the presence of divestitures due to other motives would bias the results towards no statistical relationship between exit value and CARs with the potentially erroneous implication that the option has been fully and accurately priced.

12. Kaplan and Weisbach (1992) show evidence that divestment decisions may follow acquisitions as a part of the post acquisition integration in the group or as a response to 
TABLE 2. Number of Divestiture Transactions and Breakdown by Year: UK 1985-1991

A. Number of Completed Divestitures between 1985 and 1991

\begin{tabular}{lcc} 
Criteria & $\begin{array}{c}\text { Number of firms remaining } \\
\text { at each criterion }\end{array}$ & $\begin{array}{c}\text { Number of firms eliminated } \\
\text { at each criterion }\end{array}$ \\
\cline { 1 - 1 } Initial sample & 3031 & 1917 \\
Listed Firms (1) & 1114 & 196 \\
Suspended companies & 918 & 270 \\
International Firms (2) & 648 & 60 \\
Financial Firms (3) & 588 & 357 \\
Multiple transaction (4) & 231 & 31 \\
Engaged in takeover (5) & 200 & 56 \\
Data available (6) & 144 & \\
Final sample & 144 &
\end{tabular}

B. Distribution of Completed Divestitures by Year for the Initial Sample of 3031 Divestitures and Final Sample of 144 Divestitures by UK Listed Companies Completed between 1985 and 1991.

\begin{tabular}{|c|c|c|c|c|c|}
\hline \multirow[b]{2}{*}{ Year } & \multicolumn{2}{|c|}{ Initial sample } & \multicolumn{3}{|c|}{ Final sample } \\
\hline & Number & $\begin{array}{c}\% \text { of initial } \\
\text { sample }\end{array}$ & Number & $\begin{array}{c}\% \text { of final } \\
\text { sample }\end{array}$ & $\begin{array}{c}\% \text { of initia } \\
\text { sample }\end{array}$ \\
\hline$\overline{1985}$ & 368 & 12.14 & 29 & 20.14 & 7.88 \\
\hline 1986 & 366 & 12.08 & 20 & 13.89 & 5.46 \\
\hline 1987 & 385 & 12.70 & 24 & 16.67 & 6.23 \\
\hline 1988 & 522 & 17.22 & 27 & 18.75 & 5.17 \\
\hline 1989 & 523 & 17.26 & 19 & 13.19 & 3.63 \\
\hline 1990 & 496 & 16.36 & 17 & 11.81 & 3.43 \\
\hline 1991 & 371 & 12.24 & 8 & 5.56 & 2.16 \\
\hline Total & 3031 & 100.00 & 144 & 100.00 & \\
\hline
\end{tabular}

Note: 1. Seller firms are UK companies listed on the London Stock Exchange. We assume that those firms which do not have Datastream program codes are not UK listed firms on the London Stock Exchange. 2. All International companies were excluded even if they are listed on the London Stock Exchange. Out of 270 International companies only 8 companies have the `required data. 3. Sixty financial and property firms (Bank, Insurance, Discount House, Property, Investment Trust) are excluded from the identified sample. 4. The multiple sell-off announcement that occurs in three years pre-sell-off and three years postsell-off is deleted from the list. 5. Any transaction involved in a take-over and merger activity within the three years before the sell-off and three years after the sell-off is also deleted. 6 . Data must be available for the seller 250 days pre- sell-off and 30 days post- sell-off.

suspension in trading is indicative of financial distress or some other

unsuccessful takeovers. 
corporate upheaval. Implementation of changes in company strategy can take several years to complete and financial distress can take time to overcome. Thus, we eliminated all transactions by seller firms with other sell-offs or takeovers in the three years preceeding and three years following the announcement. ${ }^{13} \mathrm{We}$ also eliminated all transactions by seller firms whose share trading was suspended in the three years preceding or following the transaction announcement.

Finally, because of the idiosyncrasies of the financial and property sectors, we eliminated all transactions by banks, insurance companies, discount houses, and real estate companies.

Table 2 gives a breakdown of the number of firms eliminated respectively each year and at each step. Panel A shows that over 1900 firms were eliminated because they were not listed on the LSE. Another large group of firms (357) were eliminated because they had multiple divestitures over the six-year window, 270 more disappeared because they were non-UK, and 196 were eliminated because of trading suspension. Panel B gives the breakdown of the initial and final samples by year. The final sample is evenly distributed across the sample period except for 1991 with only 8 transactions.

\section{B. The cumulative abnormal returns}

Event study methodology was used to generate the data on CARs. Stock returns, interest rates and market capitalization data were taken from DATASTREAM and the stock market index used in the calculation of abnormal returns was the value weighted FT-All Share Index. The market model (MM) was used in the event study to estimate abnormal returns. The basic market model methodology is that followed by Patell (1976). The abnormal return $A R$ is computed as the difference between the actual return on the shares and the expected return on the shares. To calculate the expected returns, the following equation using ordinary least squares was estimated:

$$
R_{i t}=\alpha_{i}+\beta_{i} R_{m t}+\varepsilon_{i t}
$$

13. The three year time frame was determined after examining individual companies for which information was available. We found that evidence of strategic change or financial distress went back (forward) as much as three years. 
where

$R_{i t} \quad$ is the log return of share $i$ on day $t$,

$R_{m t} \quad$ is the log return on the value weighted FT All Shares Index.

$\varepsilon_{i t} \quad$ is a mean zero, independent disturbance term in period $t$

$\alpha_{i}$ and $\beta_{i}$ are the Ordinary Least Squares parameter estimates for a given firm, $i$, computed from the 118 trading day estimation period (EP) from $t=-250$ to $t=-31 .{ }^{14}$

From equation (11) the expected return is derived as $E\left(R_{i t} / R_{m t}\right)=\alpha_{i}+$ $\beta_{i} R_{m t}$ and abnormal returns are

$$
\mathrm{AR}_{i t}=R_{i t}-E\left(R_{i t} / R_{m t}\right)
$$

An adjustment is necessary here because the parameters of the market model are estimated from observations outside the test period and, consequently, the abnormal returns in the test period will have a higher variance than the residuals in the estimation period. For this reason abnormal returns are really prediction errors rather than true residuals in the OLS sense. To account for this, we make an adjustment suggested by Patell (1976), to produce the standardized abnormal returns (SAR), which are used in our event study: $\mathrm{SAR}_{i t}=\frac{\mathrm{AR}_{i t}}{\sigma_{i} \sqrt{c_{i t}}}$ where $\sigma_{i}$ is the standard error of the abnormal returns for firm $i$ in the test period, $c_{i t}=1+\frac{1}{H}+\frac{\left(R_{m t}-E\left(R_{m}\right)\right)^{2}}{\sum_{t=1}^{H}\left(R_{m t}-E\left(R_{m}\right)\right)^{2}}, E\left(R_{m}\right)=\frac{1}{H} \sum_{t=1}^{H} R_{m t}$ and $H$ is the number of days in the estimation period.

Cumulative abnormal returns (CARs) are calculated as the sum of the daily ARt over the 'event window'. The event windows vary in length, up to a 61-day window surrounding the day of the acquisition announcement $(-30$ to +30$)$. Because of our assumption concerning the

14. The $\beta_{i}$ coefficients were also estimated using Dimson's (1979) adjusted for infrequent trading (with $\beta_{D}=\Sigma \beta_{i} / N$ ). The excess returns obtained using adjusted betas were overall very similar to those obtained without the beta adjustment, which are the ones reported in this paper. The excess returns based on adjusted beta coefficients are not reported in this paper, but are available from the authors upon request. 
TABLE 3. Descriptive Statistics for Positive Cumulative Abnormal Returns (CARs) for Firms Involved in Corporate Divestitures (1985-1991)

A. $(-1,+1)$

$\begin{array}{lc}\text { Mean } & 0.0067 \\ \text { Standard Error } & 0.0042 \\ \text { Median } & 0.0008 \\ \text { Standard Deviation } & 0.0498 \\ \text { Sample Variance } & 0.0025 \\ \text { Kurtosis } & 5.6853 \\ \text { Skewness } & 1.3423 \\ \text { Range } & 0.4000 \\ \text { Minimum } & -0.13867 \\ \text { Maximum } & 0.2613 \\ \text { Sum } & 0.9606 \\ \text { Count } & 144\end{array}$

B. $(-1,+1)$

\begin{tabular}{lcc} 
& negative CARs & positive CAR,s \\
\hline Mean & -0.0266 & 0.0391 \\
Standard Error & 0.0032 & 0.0053 \\
Median & -0.0162 & 0.0239 \\
Standard Deviation & 0.0272 & 0.0454 \\
Sample Variance & 0.0007 & 0.0021 \\
Kurtosis & 3.1934 & 8.6394 \\
Skewness & -1.6077 & 2.5276 \\
Range & 0.1381 & 0.2607 \\
Minimum & -0.1387 & 0.0006 \\
Maximum & -0.0006 & 0.2613 \\
Sum & -1.8898 & 2.8504 \\
Count & 71 & 73 \\
\hline
\end{tabular}

EMH and private information, we are interested in the announcement dates, which are those reported in Acquisitions Monthly, rather than completion dates. The announcement date is the first day on which the divestiture deal is published in the financial press and thus it is the first date when the private information becomes public. ${ }^{15} \mathrm{We}$ then look at average ARs for each day on either side of day 0 , the announcement day. The ARs for days -2 and +2 are not significant while those for -1 and +1 are. Thus, we conclude that the relevant window is $(-1,+1){ }^{16}$

15. As we noted in footnote 1 , the completion date of divestitures often preceeds or follows the public announcement date of the divestiture.

16. We checked this window for confounding announcements for the 144 divestitures in 
The descriptive data of the final sample resulting from the event study are presented in table 3 . Panel A presents the descriptive statistics for the whole series. In the testing that follows, it will be necessary to break the series into positive and negative CARs. Panel B gives the descriptive statistics for these two.

\section{Empirical results}

Equation 10 is expressed in terms of capital gains rather than returns. Our objective is to test whether the abnormal gain in the firm's market value is related to the value of the abandonment option when the exit value is made public. To get from the CARs estimated in the preceding section to capital gains, let $C G$ represent the realized abnormal capital gain and $M V_{t-1}$ the observed value of the firm at the end of the day preceding the first day of the relevant window. Then $C G$ can be calculated as $C A R \times M V_{t-1}$, where $C A R$ is the cumulative abnormal return over the relevant window. Table 4 gives the descriptive statistics for $C G$.

Substituting equation 2A from the Appendix into equation 10 shows that on the announcement date the value of the option is equal to the exit value: $F=S^{*}$. Remember that if investors have accurately priced the option, there will be no significant relationship between the option value on the announcement date and abnormal capital gains. If it has been mispriced there will be a significant relationship between the two and a one for one relationship signifies that the option has not been priced at all. Table 5 presents the results of straight tests between the exit value and the realized abnormal capital gain in the ordinary least squares (OLS) regression:

$$
\mathrm{CG}_{i}=\alpha_{0}+\beta\left\{S_{i} *\right\}+\varepsilon
$$

There is evidence that the option is being mispriced. The beta coefficient is significant at the $1 \%$ level and the $R^{2}$ is $11 \%$. When the series is broken down into positive and negative realized abnormal capital gains, most of the significance is concentrated in the positive series, which indicates that the option is being underpriced. The beta coefficient of 0.01 for the positive $C G$ s means that the exit value is underpriced by about $1 \%$. The $R^{2}$ of $22 \%$ indicates that $22 \%$ of the abnormal capital gains are explained by the underpricing of the option.

the sample and found none. 
TABLE 4. Descriptive Statistics for Abnormal Capital Gains (CG)

\begin{tabular}{lr}
\hline$(-1,+1)$ & GC \\
\hline Mean & 0.2760 \\
Standard Error & 3.2600 \\
Median & 0.0150 \\
Standard Deviation & 39.1230 \\
Sample Variance & 1530.5700 \\
Kurtosis & 83.1650 \\
Skewness & -7.2440 \\
Range & 567.3500 \\
Minimum & -404.6660 \\
Maximum & 162.6840 \\
Sum & 39.7200 \\
Count & 144 \\
\hline
\end{tabular}

The results for the negative abnormal capital gains suggest that there is no overpricing going on.

There is a possibility that our results could be biased by the presence of outliers. To reduce the influence of outliers, we follow Berger, Ofec and Swary (1996) and take logs and then retest the relationship between $C G$ and $S$ :

$$
\ln \left(C G_{i}\right)=\alpha_{0}+\beta \ln \left\{S_{i}^{*}\right\}+\varepsilon
$$

The results in table 6 now show the existence of both underpricing and overpricing. The results for positive $C G$ s confirm the underpricing detected in table 5. The relationship between positive abnormal capital gains and exit value is less than one for one and the coefficient is significant at the $1 \%$ level. It is interesting to note that, as predicted, there is a negative relationship between exit value and the negative abnormal capital gains (a positive coefficient signifies a negative relationship since we take the log of the absolute value of the negative abnormal capital gains). The beta coefficient for exit value estimated for negative $C G$ s is significant, which is evidence that overpricing has occurred and that the abnormal capital losses are due to the losses associated with premature abandonment: $S-F \cdot{ }^{17}$ The overall results, however, are much weaker than for the positive abnormal $C G \mathrm{~s} .{ }^{18}$

17. For example, ceteris paribus, for an at the money option, $S-F$ will be greater if $S=$ 20 than if $S=15$.

18. As a robustness check for possible omitted variable bias, we re-did all the tests 
TABLE 5. Regression Results

\begin{tabular}{|c|c|c|c|c|c|c|c|c|}
\hline \multicolumn{9}{|c|}{$C G_{i}=\alpha_{0}+\beta\left\{S_{i}^{*}\right\}+\varepsilon$} \\
\hline \multicolumn{3}{|c|}{ Positive and Negative $C G$} & \multicolumn{3}{|c|}{ Positive $C G$} & \multicolumn{3}{|c|}{ Negative $C G$} \\
\hline$\alpha$ & $\beta$ & $R^{2}$ & $\alpha$ & $\beta$ & $R^{2}$ & $\alpha$ & $\beta$ & $R^{2}$ \\
\hline $\begin{array}{l}4.96 \\
(1.51)\end{array}$ & $\begin{array}{l}-0.07 \\
(-4.10) * * *\end{array}$ & 0.11 & $\begin{array}{l}9.79 \\
(3.27) * * *\end{array}$ & $\begin{array}{l}0.01 \\
(4.47)^{* * *}\end{array}$ & 0.22 & $\begin{array}{l}-0.85 \\
(-0.15)\end{array}$ & $\begin{array}{l}-0.12 \\
(-0.42)\end{array}$ & 0.03 \\
\hline
\end{tabular}

Note: $\mathrm{t}$-statistics in parentheses. $* * *$ Significantly different from zero at the $1 \%$ level, using a two-tailed t-test. ** Significantly different from zero at the 5\% level, using a two-tailed t-test. * Significantly different from zero at the $10 \%$ level, using a two-tailed t-test.

To test whether the timing factor contributes to the mispricing of the abandonment option, equation (10) estimated on the announcement date is used to generate the timing factor. From the value matching and smooth pasting conditions (equations A2 and A3 in the Appendix), $g=$ $g^{*}$ on the announcement date. At $g=g^{*}, f\left(g^{*}\right)=1$. Thus, the full value of the divestable assets is calculated as $F=S^{*} f\left(g^{*}\right)=S^{*}$, where $S^{*}$ represents the observed exit value of the transaction. Equation (10) gives the "true" value of the divested assets based on the private information held by the managers. Thus, the theoretical capital gain is equal to the "true" value of the assets estimated in equation (10) at $g^{*}$ minus the value of the assets at $g^{*}$ estimated by the market in the absence of the complete information. The value of the assets at $g^{*}$, noted as $V^{*}$, are equal to $S^{*} g^{*}$. Thus, the theoretical capital gain can be written as $S^{*}\left[1-g^{*}\right]$. To see this, remember that $g=V / S$. From the boundary condition (A2) it is known that $f\left(g^{*}\right)=1$. From equation (10) we have $F=S f$. Thus, $S^{*} f\left(g^{*}\right)-S^{*} g^{*}=S^{*}\left(1-g^{*}\right)=S^{*}\left(1-(V / S)^{*}\right)=$ $S^{*}-V^{*}$, where $g^{*}=\frac{\eta_{2}}{\eta_{2}-1}\left[\frac{r(\kappa+\gamma)}{\kappa(r+\gamma)}\right]$.

The estimation of $g^{*}$ requires estimates of the parameters for $S$ and $V$ in equations (7) and (9). The exit value, $S$, is observable but only on the transaction date and we can observe neither $V$ nor $V^{*}$. Thus, to estimate $g^{*}$ we assume that $S$ is constant and equal to the observable value on the exercise date so that $\mu=\alpha$ and $\delta^{2}=\sigma^{2}$. To obtain estimates of the parameters for $V$, we note that our data set deals with same

controlling for gross leverage, net leverage, the interest cover ratio, Tobin's q, capital expenditure/sales, and cash and cash equivalents/current liabilities. None of these variables were significant at the $10 \%$ level and the adjusted R-squares were generally lower while the significance of the $\mathrm{S}$ coefficient was qualitatively unchanged. 
TABLE 6. Regression Results

\begin{tabular}{|c|c|c|c|c|c|c|c|c|}
\hline \multicolumn{9}{|c|}{$\ln \left|C G_{i}\right|=\alpha_{0}+\beta \ln \left\{S_{i}^{*}\right\}+\varepsilon$} \\
\hline \multicolumn{3}{|c|}{ Positive and Negative $C G$} & \multicolumn{3}{|c|}{ Positive $C G$} & \multicolumn{3}{|c|}{ Negative $C G$} \\
\hline$\alpha$ & $\beta$ & $R^{2}$ & $\alpha$ & $\beta$ & $R^{2}$ & $\alpha$ & $\beta$ & $R^{2}$ \\
\hline $\begin{array}{l}-0.42 \\
(-1.92)^{*}\end{array}$ & $\begin{array}{l}0.27 \\
(3.36)^{* * * *}\end{array}$ & 0.07 & $\begin{array}{l}3.44 \\
(9.42)^{* * *}\end{array}$ & $\begin{array}{l}0.35 \\
(4.48)^{* * *}\end{array}$ & 0.20 & $\begin{array}{l}-2.39 \\
(-9.21)^{* * *}\end{array}$ & $\begin{array}{l}0.23 \\
(2.38)^{* *}\end{array}$ & 0.07 \\
\hline
\end{tabular}

Note: $\mathrm{t}$-statistics in parentheses. $* * *$ Significantly different from zero at the $1 \%$ level, using a two-tailed t-test. ** Significantly different from zero at the 5\% level, using a two-tailed t-test. * Significantly different from zero at the $10 \%$ level, using a two-tailed t-test.

industry divestitures. ${ }^{19}$ Based on this, we make the plausible assumption that $V$ mimics the divesting firm and, consequently, has the same parameters. Thus, we use the historical data of the firm from -250 to -31 to estimate the relevant parameters for $V$ with $\kappa=R-\alpha$ equal to the dividend rate, ${ }^{20} \delta^{2}=\sigma^{2}$ equal to the historical variance of the percentage change in the firm's market value and $r$ equal to the treasury bill rate. Since $\gamma$, the premature exit parameter, is also unobservable our first estimate of $g^{*}$ sets $\gamma$ equal to zero.

As noted above, investor overpricing of the abandonment option suggests premature abandonment rather than optimal timing. Thus, the timing factor should only be relevant for positive abnormal capital gains. We take $\operatorname{logs}$ and test the following ordinary least squares regressions on the positive abnormal capital gains:

$$
\begin{gathered}
\ln \left(C G_{i}\right)=\alpha_{0}+\beta \ln \left\{S_{i} *\left[1-g_{i} *\right]\right\}+\varepsilon \\
\ln \left(\mathrm{CG}_{i}\right)=\alpha_{0}+\beta_{1} \ln \left\{S_{i} *\right\}+\beta_{2} \ln \left(1-g^{*}\right)+\varepsilon
\end{gathered}
$$

Equation 15 tests whether the theoretical capital gain plays a role in how investors price the option. Equation 16 tests whether the timing factor is significant as a stand-alone explanatory variable. The results of these regressions are summarized in table 7. Comparing panel A with

19. We verify that each divestiture is in the same industry as the parent as follows. The seller firms and divestitures were set up on the Datastream program 80A and classified into respective industries using Datastream industrial classification level 4.

20. For firm's paying no dividend we estimated the convenience yield as equal to the average dividend yield of the dividend paying firms in the sample for each window. 
TABLE 7. Regression Results of Positive Realized Capital Gain on Exit Value and the Timing Factor

A. Realised Capital Gain as a Function of the Theoretical Capital Gain

\begin{tabular}{lcc}
\multicolumn{3}{c}{$\ln \left(C G_{i}\right)=\alpha_{0}+\beta \ln \left\{S_{i}^{*}\left[1-g_{i}^{*}\right]\right\}+\varepsilon$ with $(\gamma=0)$} \\
\hline$\alpha$ & $\beta$ & $R^{2}$ \\
1.43 & 0.34 & 0.20 \\
$(7.26)^{* * *}$ & $(4.39)^{* * *}$ &
\end{tabular}

B. Realised Capital Gain as a Function of Exit Value and the Timing Factor

\begin{tabular}{lccc}
\multicolumn{4}{c}{$\ln \left(C G_{i}\right)=\alpha_{0}+\beta_{1} \ln \left\{S_{i}^{*}\right\}+\beta_{2} \ln \left(1-g^{*}\right)+\varepsilon$ with $(\gamma=0)$} \\
\hline$\alpha$ & $\beta_{1}$ & $\beta_{2}$ & $\operatorname{Adj} R^{2}$ \\
1.49 & 0.28 & 3.35 & 0.13 \\
$(1.06)$ & $(2.84)^{* * *}$ & $(1.43)$ & \\
\hline
\end{tabular}

Note: $\mathrm{t}$-statistics in parentheses. $* * *$ Significantly different from zero at the $1 \%$ level, using a two-tailed t-test. $* *$ Significantly different from zero at the $5 \%$ level, using a two-tailed t-test. * Significantly different from zero at the $10 \%$ level, using a two-tailed t-test.

the results for positive $C G$ s in table 6 , there is very little difference. The beta coefficient is still significant at the $1 \%$ level and differs by only 0.01 and the $R^{2}$ is unchanged. Thus, although the timing factor does not seem to add much, it does not take anything away either. It is neutral, so to speak. In Panel B the beta coefficient for the timing factor is not significant. ${ }^{21}$ This is evidence that the effects of the timing factor have been fully priced by investors.

To examine the potential role of premature exit risk on the timing of divestiture, an estimate of $\gamma$ for each firm is required. To get estimates for the individual $\gamma$ 's, the following procedure was implemented. First, $g^{*}$ was recalculated as before but with a positive $\gamma$ common to all firms. This calculation was repeated twenty times, letting $\gamma$ vary in steps of 0.001 between 0.001 and $0.02 .{ }^{22}$ Then equation 15 was re-estimated over all intervals with the modified values of $g^{*}$ in order to find the best "average gamma" based on $R^{2}$ and the t-statistic for the explanatory

21. As a robustness check on the sensitivity of $\beta^{2}$ to a potential measurement error bias in the variable $g^{*}$, we re-estimated equation 16 with 20 different estimates of $g^{*}$ by letting $\gamma$ vary in steps of 0.001 between 0.001 and 0.02 . The results are unchanged. The coefficient $\beta^{2}$ is never significant at the $10 \%$ level.

22. This is the interval that respects the boundary conditions for all positive CAR firms such that $g^{*}<1$. 
TABLE 8. Regression Results: Realised Capital Gain as a Function of the Theoretical Capital Gain Estimated with a Firm Specific $\gamma$

\begin{tabular}{lcc}
\hline \multicolumn{3}{c}{$\ln \left(C G_{i}\right)=\alpha_{0}+\beta \ln \left\{S_{i}^{*}\left[1-g_{i}{ }^{*}\right]\right\}+\varepsilon$} \\
\hline$\alpha$ & $\beta$ & $R^{2}$ \\
0.74 & 0.35 & 0.17 \\
$(3.07)^{* * *}$ & $(3.72)^{* * *}$ & \\
\hline
\end{tabular}

Note: *** Significantly different from zero at the $1 \%$ level, using a two-tailed t-test. ** Significantly different from zero at the $5 \%$ level, using a two-tailed t-test. * Significantly different from zero at the $10 \%$ level, using a two-tailed t-test.

variable. The results not reported here show that the value of gamma that gave the best overall performance based on $R^{2}$ and the t-statistic for $\beta$ was $\gamma=0.01 .{ }^{23}$

This result was used to estimate the individual gammas for each firm. To do this, it was assumed that gamma is proportional to the firm's variance, the argument being that larger fluctuations are indicative of more extreme situations that will trigger premature exit both on the downside such as a liquidity crisis that uses divestiture to generate cash or on the upside such as an investment opportunity that makes the ongoing project redundant or uses divestiture as a financing mechanism. ${ }^{24}$ Then equation (15) was re-estimated with the $g^{*} \mathrm{~s}$ estimated with the firm specific gammas.

The results, summarized in table 8 , show that the $\beta$ coefficient is significant. This suggests that the firm specific $\gamma$ 's might be relevant in explaining managerial maximizing behavior. The results are mixed at best, however, if the results of table 8 are compared with those of table 7 , panel A where $\gamma=0$. The significance level of the $\beta$ coefficient is lower in table 8 and the overall explanatory power of the equation in table 8 , reflected in the $R^{2}$, is also lower. The results not reported here

23. The results are available on request.

24. The estimation of gamma was effected in the following manner. Let $k$ represent the proportionality factor and $\delta_{i}^{2}$ the variance of firm $i, i=1,2, \ldots n$. Since the average gamma is $1 \%$ we write $k \frac{1}{n} \sum_{i=1}^{n} \delta_{i}^{2}=0.01$. Thus, $k=0.01(n) / \sum_{i=1}^{n} \delta_{i}^{2}$. Knowing $k$, we estimate gamma as $\gamma_{i}=k \delta_{i}^{2}$. 
show that the gamma specific time factors are not statistically significant for any of the windows. Thus, if premature divestiture does play a role in the pricing of the abandonment option, its effects are fully priced by investors.

\section{Conclusions}

Investors have the option to abandon assets for their exit value when the present value of expected cash flows accruing from these assets is deemed inadequate to justify their continued utilization. According to theory, this option can be priced as an American style put whose value increases with exit value. However, divestitures are negotiated in such a way that the exact amount of the exit value, might remain private information until the deal is actually announced. Consequently, if the strong form of the EMH does not hold and the exact amount of the exit value is private information, investors will be unable to price the abandonment option accurately until the private information becomes public. This paper developed a model for valuing the abandonment option and used it to test whether and how accurately investors price the abandonment option. An event study was effected in order to calculate the abnormal returns realized around the announcement of the divestiture. The abnormal capital gains identified in the event study were then tested against the theoretical capital gains derived from the option pricing model to determine whether and how accurately the theoretical capital gains explain the realized abnormal capital gains. The general conclusion is that investors do price the abandonment option but, because the actual exit value is private information and the strong form of the EMH does not hold, they tend to misprice it. There is evidence of both under and over pricing and our results suggest that overpricing is associated with premature investment. Our results also suggest that the effects of the timing factor are accurately priced by investors. There is weak evidence that the possibility of premature abandonment figures in the pricing of the abandonment option and that investors accurately assess its effects.

Accepted by: Prof. L. Trigeorgis, Guest Editor, March 2008

Prof. P. Theodossiou, Editor-in-Chief, March 2008 


\section{Appendix}

The general solution to (5) is

$$
f=\frac{\kappa}{\kappa+\gamma} g+\frac{\gamma}{r+\gamma}+K_{1} g^{\eta_{1}}+K_{2} g^{\eta_{2}}
$$

where $\eta_{1}>1$ (because $\kappa=0$ ) and $\eta_{2}>0$ are the roots to the quadratic equation in $\eta$ :

$$
\eta_{1}, \eta_{2}=\frac{-\left(r-\kappa-\delta^{2} / 2\right) \pm \sqrt{\left(r-\kappa-\delta^{2} / 2\right)^{2}+2 \delta^{2}(r+\gamma)}}{\delta^{2}}
$$

Since the investment will not be abandoned as $g$ gets larger and larger, $K_{1}=0$. The value of $f$ depends then on $g^{*}$. The value matching condition is

$$
f\left(g^{*}\right)=1
$$

and the smooth pasting condition is

$$
f^{\prime}\left(g^{*}\right)=0
$$

Substituting and solving simultaneously gives the equation in the text.

\section{References}

Afshar, K. A; Taffler, R. J.; and Sudarsanam, P. S. 1992. The Effect of Corporate Divestment on Shareholders' Wealth: The UK Experience. Journal of Banking and Finance 16: 115-135.

Alexander, J. G.; Benson, P. G.; and Kampmeyer, J. M. 1984. Investigation the Valuation Effects of Announcements of Voluntary Corporate Sell-offs. The Journal of Finance 39 (2): 503-517.

Alexandrou, G., and Sudarsanam, S. 2001. Share Holder Wealth Effects of Corporate Selloffs: Impact of Growth Opportunities, Economic Cycle and Bargaining Power. European Financial Management 7 (2): 237-258.

Arshadi, N., and Eyssell, T. 1993. The Law and Finance of Corporate Insider Trading: Theory and Evidence. Boston: Kluwer Academic Publishers.

Berger, P.G; Ofek, E.; and Swary, I. 1996. Investor Valuation of the 
Abandonment Option. Journal of Financial Economics 42: 257-287.

Boudreaux, J. K. 1975. Divestiture and Share Price. Journal Of Financial and Quantitative Analysis 10 (November): 619-626.

Brennan, M., and Schwartz, E. 1985. Evaluating Natural Resource Investments. Journal of Business (2): 135-157.

Comment, R., and Jarrell, G. A. 1995. Corporate Focus and Stock Returns. Journal of Financial Economics 37: 67-87.

Darby, J.; Hughes Hallett, A. J.; Ireland, J.; and Piscitelli, J. 1999. The Impact of Exchange Rate Uncertainty on the Level of Investment. Economic Journal 109: C55-C57.

Denning, C. K. 1988. Spin-offs and Sales of Assets: An Examination of Security Returns and Divestment Motivations. Accounting and Business Research 19 (37): 32-42.

Denning, C. K., and Shastri, K. 1990. Single Sale Divestments: The Impact on Stockholders and Bondholders. Journal of Business Finance \& Accounting 17 (5) (Winter): 731-743.

Dimson, E. 1979. Risk Measurement When Shares Are Subject to Infrequent Trading. Journal of Financial Economics 17: 197-226.

Dixit, A. K., and Pindyck, R. S. 1994. Investment under Uncertainty Princeton, NJ: Princeton University Press.

Dyl, E., and Long, H. 1969. Abandonment Value and Capital Budgeting: Comment. Journal of Finance 24 (1): 88-95.

Gadad, A. M. 1998. The Effect of Divestitures on Firms Operating Performance and Shareholders' Wealth: UK Evidence Unpublished Doctoral Dissertation, University of Essex.

Hearth, D., and Zaima, J. K. 1984. Voluntary Corporate Divestitures and Value. Financial Management 13: 10-16.

Hirschey, M., and Zaima, J. K. 1989. Insider Trading, Ownership Structure, and the Market Assessment of Corporate Sell-offs. Journal of Finance 44 (4): 971-980.

Hite, L. G.; Owers, J. E.; and Rogers, R. C. 1987. The Market for Interfirm Asset Sales: Partial Sell-offs and Total Liquidations. Journal of Financial Economics 18: 229-252.

Jain, P. 1986. The Effects of Voluntary Sell-off Announcements on Shareholder Wealth. The Journal of Finance 40 (1): 209-224.

John, K., and Ofek, E. 1995. Asset Sales and Increases in Focus. Journal of Financial Economics 37: 105-126.

Johnson, H.E. 1987. Options on the Maximum or the Minimum of Several Assets. Journal of Financial and Quantitative Analysis 22: 277-284.

Kaiser K. M. J., and Stouraitis, A. 2001. Agency Costs and Strategic Considerations behind Sell-offs: the UK Evidence. European Financial Management 7: 319-349.

Kaplan, N. S., and Weisbach, M. S. 1992. The Success of Acquisitions: Evidence from Divestitures. The Journal of Finance 47: 107-138. 
Klein, A. 1986. The Timing and Substance of Divestiture Announcements: Individual, Simultaneous and Cumulative Effects. The Journal of Finance 41: 685-697.

Kummer, R. D. 1978. Valuation Consequences of Forced Divestiture Announcements. Journal of Economics and Business 24: 130-136.

Lang, L.; Poulsen, A.; and Stulz, R. 1995. Asset Sales, Firm Performance, and the Agency Costs of Managerial Discretion. Journal of Financial Economics 37: 3-37.

Lasfer, M.; Sudarsanam, O. S.; and Taffler, R. 1996. Financial Distress, Asset Sales and Lender Monitoring 1996. Financial Management 25: 57-66.

Margrabe, W. 1978. The Value of an Option to Exchange One Asset for Another. Journal of Finance, 33: 177-186.

McDonald, R., and Siegel, D. 1985. Investment and the Valuation of Firms when There is an Option to Shut Down. International Economic Review 26: 331-349.

Montgomery, A. C.; Thomas, A. R.; and Kamath, R. 1984. Divestiture, Market Valuation and Strategy. Academy of Management Journal (December): 830-41.

Myers, S.C., and Majd, S. 1990. Abandonment Value and Project Life', Advances in Futures and Options Research 4: 1-21.

Paddock, J.; Siegel, D.; and Smith, J. 1988. Option Valuation of Claims on Real Assets : The Case of Offshore Petroleum Leases. Quarterly Journal of Economics 103: 479-508.

Patell, J.M. 1976. Corporate Forecasts of Earnings Per Share and Stock Price Behavior: Empirical Tests. Journal of Accounting Research 14: 246-276.

Quigg, L. 1993. Empirical Testing of Real Option-Pricing Models', Journal of Finance 48: 621-640.

Robichek, A., and VanHorne, J. 1967. Abandonment Value and Capital Budgeting. Journal of Finance 22: 577-590.

Rosenfeld, D. J. 1984. Additional Evidence on the Relation Between Divestiture Announcements and Shareholder Wealth. The Journal of Finance 39: 1437-1448.

Stulz, R. 1982. Options on the Minimum or the Maximum of Two Risky Assets. Journal of Financial Economics 10: 161-185.

Tehranian, H.; Travlos, N. G.; and Waegelein, J. F. 1987. The Effect of Long-Term Performance Plans on Corporate Sell-Off-Induced Abnormal Returns. The Journal of Finance 42:. 933-942. 